\title{
The ozonolysis of primary aliphatic amines in fine particles
}

\author{
J. Zahardis, S. Geddes, and G. A. Petrucci \\ Department of Chemistry, University of Vermont, Burlington, VT 05405, USA \\ Received: 19 September 2007 - Published in Atmos. Chem. Phys. Discuss.: 15 October 2007 \\ Revised: 20 December 2007 - Accepted: 20 December 2007 - Published: 29 February 2008
}

\begin{abstract}
The oxidative processing by ozone of the particulate amines octadecylamine (ODA) and hexadecylamine (HDA) is reported. Ozonolysis of these amines resulted in strong $\mathrm{NO}_{2}^{-}$and $\mathrm{NO}_{3}^{-}$ion signals that increased with ozone exposure as monitored by photoelectron resonance capture ionization aerosol mass spectrometry. These products suggest a mechanism of progressive oxidation of the particulate amines to nitroalkanes. Additionally, a strong ion signal at $125 \mathrm{~m} / \mathrm{z}$ is assigned to the ion $\mathrm{NO}_{3}^{-}\left(\mathrm{HNO}_{3}\right)$. For ozonized mixed particles containing ODA or HDA + oleic acid (OL), with $p_{\mathrm{O}_{3}} \geq 3 \times 10^{-7}$ atm, imine, secondary amide, and tertiary amide products were measured. These products most likely arise from reactions of amines with aldehydes (for imines) and stabilized Criegee intermediates (SCI) or secondary ozonides (for amides) from the fatty acid. The routes to amides via SCI and/or secondary ozonides were shown to be more important than comparable amide forming reactions between amines and organic acids, using azelaic acid as a test compound. Finally, direct evidence is provided for the formation of a surface barrier in the ODA + OL reaction system that resulted in the retention of OL at high ozone exposures (up to $10^{-3} \mathrm{~atm}$ for $17 \mathrm{~s}$ ). This effect was not observed in HDA + OL or single component OL particles, suggesting that it may be a species-specific surfactant effect from an in situ generated amide or imine. Implications to tropospheric chemistry, including particle bound amines as sources of oxidized gas phase nitrogen species (e.g. $\mathrm{NO}_{2}, \mathrm{NO}_{3}$ ), formation of nitrogen enriched HULIS via ozonolysis of amines and source apportionment are discussed.
\end{abstract}

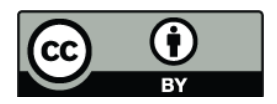

Correspondence to: G. A. Petrucci (Giuseppe.Petrucci@uvm.edu)

\section{Introduction}

Amines, including aliphatic amines, represent an important contributor to organic nitrogen in the atmosphere and stem from both anthropogenic and biogenic emissions. Animal husbandry is probably the most important anthropogenic emission source of amines into the troposphere (Filipy et al., 2006; Rabaud et al., 2003), with Schade and Crutzen (Schade and Crutzen, 1995) having estimated contributions up to $108 \pm 30$ and $24 \pm 15 \mathrm{Gg} \mathrm{Nyr}^{-1}$ for trimethylamine and methylamine to the atmosphere, respectively; albeit this is still 2-3 orders of magnitude lower than ammonia (23.3 $\mathrm{Tg} \mathrm{Nyr}^{-1}$ ). Agriculture (Beddows et al., 2004) and biomass burning (Decesari et al., 2006; Mace et al., 2003) may also be important sources of amines to the troposphere. Other anthropogenic sources of amine or amine-derived nitrogen to the troposphere include vehicular emissions (Angelino et al., 2001), industrial processes, and cooking (Rogge et al., 1991; Schauer et al., 1999). In the marine troposphere organic amine nitrogen, including amino acids, may enter the troposphere via a bubble bursting mechanism at the air-sea interface (Milne and Zika, 1993). Other biogenic sources of organic nitrogen, including amines, are addressed in the assessment provided by Neff and coworkers (Neff et al., 2002).

There is growing evidence that organic nitrogen, including amines and amine-derived compounds, may form a substantial fraction of the organic aerosol load as evidenced in recent field studies in remote (Mäkelä et al., 2001; Beddows et al., 2004), urban (McGregor and Anastasio, 2001; Simoneit et al., 2003; Angelino et al., 2001; Tan et al., 2002), and agricultural (McGregor and Anastasio, 2001; Angelino et al., 2001) regions, and in regions near extensive biomass burning (Decesari et al., 2006; Mace et al., 2003; Simoneit et al., 2003).

Gas phase aliphatic amines may play a role in secondary aerosol formation (Murphy et al., 2007; Angelino et al., 2001) via photooxidation and gas-to-particle conversion. Recent field observations have positively correlated episodic aerosol formation events with elevated concentrations of

Published by Copernicus Publications on behalf of the European Geosciences Union. 
atmospheric amines. For example, Tan et al. have found in one episodic event of elevated $\mathrm{PM}_{2.5}$ in an urban environment that organic amines were evident in all the particulate (Tan et al., 2002). Similarly, in remote boreal forest studies, Mäkelä and coworkers (Mäkelä et al., 2001) found a strong positive correlation between new particle formation events and the concentration of dimethylammonium (the ionic component of dimethylamine). This amine-derived species had more than 30-fold greater concentration during particle formation events as opposed to non-event concentrations for accumulation mode particles. In light of these recent findings, we believe that the role of amines and other forms of organic nitrogen in new particle formation events merits further investigation.

There is a need to develop a better model of the tropospheric chemical processing of amines and amine nitrogen, including understanding its incorporation into high molecular weight matter, such as humic like substances (i.e. HULIS) (Decesari et al., 2006; Likens and Galloway, 1983) found in aerosols and hydrometeors. Answering questions about how nitrogen is incorporated into HULIS and its subsequent atmospheric processing is important in developing a better understanding of the aging of fine particulate matter in the troposphere. This processing may have implications on the cloud condensation nuclei ability of these particles, affecting global climate through indirect aerosol effects (Lohmann and Feichter, 2005) through the formation of more polar, water soluble compounds in aerosols. Moreover, developing a more comprehensive model of how amines and other classes of organic nitrogen are processed in atmospheric particles will give us a better description of the deposition of nitrogen, and most broadly, better elucidate the role of organic nitrogen in the global nitrogen cycle - an area of high uncertainty and great concern (Galloway et al., 2004; Neff et al., 2002).

Herein, we report on the heterogeneous ozonolysis of two long-chain, primary, aliphatic amines (octadecylamine, ODA; and hexadecylamine, HDA) in single component and mixed fine mode particles. These high molecular weight, low-volatility amines were chosen as model systems to minimize particle-to-gas phase partitioning, such that we could study their condensed phase reactivity in the aerosol. The second constituent in the two-component particles is either oleic acid (i.e. cis-9-octadecenoic acid, OL) or dioctyl sebacate (i.e. bis(2-ethylhexyl) sebacate, DOS). OL is a logical constituent for these particles in that it, and other fatty acids, are ubiquitous in the troposphere, forming coatings on continental aerosols (Tervahattu et al., 2005) and marine particulate matter (Tervahattu and Juhanoja, 2002; Kawamura et al., 2003; Mochida et al., 2002), and are present in urban atmospheres as cooking (Robinson et al., 2006; Rogge et al., 1991; Schauer et al., 2002; Zhao et al., 2007) and combustion (Wang et al., 2006) emissions. Moreover, OL was chosen as a constituent for the mixed particles studies to investigate the reactivity of the products of ozonolysis of a common unsaturated fatty acid with the amines. As of late, a great deal of effort has gone into understanding the secondary chemistry resulting from the ozonolysis of unsaturated fatty acids (Zahardis et al., 2005; Ziemann, 2005; Hearn et al., 2005; Reynolds et al., 2006; Hung et al., 2005; Gross et al., 2006) and OL has emerged as a model compound for describing the heterogeneous ozonolysis of particulate rich in fatty acid content (for example, see review by Zahardis and Petrucci, 2007). The products of this secondary chemistry generally stem from the high reactivity of stabilized Criegee intermediates (SCI) and include high molecular weight, peroxidic oligomers (Reynolds et al., 2006; Hung and Ariya, 2007; Zahardis et al., 2006a; Katrib et al., 2005; Hung et al., 2005; Gross et al., 2006; Hearn et al., 2005; Ziemann, 2005). These types of products may have a role in the experimentally observed increase in hygroscopicity and CCN activation of fine organic particles with ozonation (Broekhuizen et al., 2004; Shilling et al., 2007; King et al., 2004; Hung and Ariya, 2007). Conversely, DOS and similar high molecular weight esters (i.e. dioctyl adipate) are common constituents in studies of organic particles (Ziemann, 2005;Mochida et al., 2006) that are not a source of SCI and inert to ozone (Mochida et al., 2006); hence, DOS serves as an excellent negative control for comparison to the studies of ozonized mixed particles of amines with OL.

Two specific goals of this work were to: a) identify chemical classes that may act as particle bound nitrogen sinks and that are representative of oxidatively stressed particulate matter; and b) compare the products formed from heterogeneous ozonolysis of particle bound alkyl amines with gas phase and solution chemistries. From this we hope to begin to better describe the atmospheric aging process of particles rich in organic nitrogen; identify chemical classes that may act potential molecular markers; and elucidate possible routes to nitrogen-rich HULIS formation.

\section{Experimental method}

In this work we describe flow reactor based experiments employing photoelectron resonance capture ionization aerosol mass spectrometry (PERCI AMS), described in detail elsewhere (LaFranchi and Petrucci, 2006). Briefly, molecular ionization by capture of low energy photoelectrons is a soft process that affords minimal fragmentation of the oxidized products with a high sensitivity for many oxygenated classes (LaFranchi and Petrucci, 2004, 2006) allowing for relatively straight-forward mass spectral interpretation and subsequent product identification and mechanism development. Two modes of ionization have been described with near $0 \mathrm{eV}$ photoelectron attachment to organic molecules, namely associative (or non-dissociative) and dissociative electron attachment. In associative electron attachment a low energy photoelectron attaches to the molecule without any fragmentation of the analyte in the ionization process; whereas, dissociative electron attachment results in the loss of an 
atomic or molecular fragment concomitant to ionization of the analyte (LaFranchi et al., 2004; Zahardis et al., 2005, 2006c, b).

Polydisperse aerosols were generated using a glass, concentric pneumatic nebuliser (J. E. Meinhard Associates, Santa Ana, CA, USA) and the solvent (100\% ethanol) was removed by passing the particle beam through a $\sim 1 \mathrm{~m}$ columnar diffusion dryer packed with silica and activated charcoal. Although the activated charcoal has been shown to remove most of the ethanol from particles (Hrvačić et al., 2006c), there may have been a small amount of residual ethanol left on the particles when ozonized. Aerosol number and mass size distributions were measured with a scanning mobility particle sizer (Model SMPS 3080, TSI Inc., Shoreview, MN) coupled with a condensation particle counter (Model 3010, TSI Inc., Shoreview, MN). In this work, both single and multicomponent particles were investigated composed of ODA ( $\geq 99 \%$, Fluka, Seelze, Germany), HDA ( $\geq 99.0 \%$, Fluka, Seelze, Germany), OL ( 99\%, Sigma-Aldrich, St. Louis, MO), azelaic acid (98\%, Sigma-Aldrich, St. Louis, MO), DOS ( $\geq 97 \%$, Fluka, Seelze, Germany). The geometric mean diameters and standard deviations of the particles were: $\mathrm{OL}$ (93.6 nm, 1.68), ODA ( $94.5 \mathrm{~nm}, 1.64)$, ODA + OL ( $98.6 \mathrm{~nm}$, 1.59), HDA + OL (108 nm, 1.71), ODA + azelaic acid + DOS $(103 \mathrm{~nm}, 1.66)$. Typical particle number densities were on the order of $10^{7} \mathrm{~cm}^{-3}$. 1-nitrohexane (98\%, Sigma-Aldrich, St. Louis, MO) was used to investigate gas phase ionization of nitroalkanes.

Particles were introduced into a concentric glass flow reactor $(2.54 \mathrm{~cm} \mathrm{i.} \mathrm{d.)} \mathrm{via} \mathrm{a} \mathrm{glass} \mathrm{tube}(3 \mathrm{~mm} \mathrm{i.} \mathrm{d.)} \mathrm{form-}$ ing the movable aerosol injector. The flow rate in the reactor was held constant at $0.9 \mathrm{~L} \mathrm{~min}^{-1}$, such that positioning the aerosol injector from 1 to $51 \mathrm{~cm}$ from the end of the flow reactor resulted in reaction times from 0 to $17 \mathrm{~s}$. Ozone was generated from USP Medical Air (UN1002, Airgas East, Williston, VT) or USP Oxygen (UN1072, Airgas East, Williston, VT) below and above $1 \times 10^{-4}$ atm respectively, by high frequency corona discharge (OL80A/DLS, OzoneLab, Burton, BC, Canada) and quantified spectrophotometrically as described in an earlier report (Zahardis et al., 2006c). Particles entered the PERCI AMS through a $260 \mu \mathrm{m}$ critical orifice giving a flow rate of $0.5 \mathrm{~L} \mathrm{~min}^{-1}$ and were introduced into the mass spectrometer through a differentially pumped particle inlet and focused into a beam using a series of aerodynamic lenses described elsewhere (Petrucci et al., 2000; Liu et al., 1995b, a). The focused particle beam was targeted onto a coiled Nichrome filament (LaFranchi and Petrucci, 2006) that could be heated resistively. For all experiments in this study the particle deposition time onto the filament was $2.5 \mathrm{~min}$. After deposition, the filament temperature was ramped from room temperature to $400^{\circ} \mathrm{C}$ over $10 \mathrm{~s}$ and then held at this temperature for $50 \mathrm{~s}$. Anion mass spectra were recorded with a time-of-flight mass spectrometer (R. M. Jordan Inc., Grass Valley, CA, USA) operating in reflectron mode.
Although the emphasis of this work was on investigating the heterogeneous processing of amines in particles, gas phase 1-nitrohexane was studied to better understand the fragmentation of aliphatic nitrocompounds by ionization with $\sim 0 \mathrm{eV}$ photoelectrons. In these studies the analyte was introduced into the ionization region of the mass spectrometer with a precision leak valve (model ULV-150, MDC Vacuum Products Corp., Hayward, CA).

\section{Results}

3.1 PERCI AMS ion profiles of the aliphatic amines, ODA and HDA, in single component particles and mixed particles of ODA (HDA) + DOS

The characteristic PERCI AMS profile for ozonized singlecomponent particles consisting of primary, aliphatic amines was initially established under low and high ozone exposures (Fig. 1a, b, respectively). Both ozonized ODA and HDA (not shown) are characterized by very strong $\mathrm{NO}_{2}^{-}(46 \mathrm{~m} / \mathrm{z})$ and $\mathrm{NO}_{3}^{-}(62 \mathrm{~m} / \mathrm{z})$ signals. $\mathrm{A} \mathrm{NO}_{2}^{-}$signal is evident with and without ozone exposure in single particles of the amines and all mixed particles containing the amines (i.e. OL + ODA (HDA), DOS + ODA (HDA)). However, in all unexposed particles the $\mathrm{NO}_{2}^{-}$signal was weak, at about $10 \%$ or less than for ozonized particles. The $\mathrm{NO}_{2}^{-}$signal is absent when all oxygen is removed from the system (i.e. both $\mathrm{O}_{2}$ and $\mathrm{O}_{3}$ are absent), namely when the nebuliser and carrier gases are $\mathrm{N}_{2}$ or Ar. This implies that the volatilization of primary aliphatic amines in the presence of any oxygen may be a minor channel to $\mathrm{NO}_{2}$ formation, compared to its direct formation via the oxidation of the amine by ozone. As shown in Fig. 2, the $\mathrm{NO}_{2}$ most likely originates from progressive oxidation by ozone of the amine to the alkylhydroxylamine, then to the nitrosoalkane, and finally to the nitroalkane. This pathway is similar to the mechanism proposed for the ozonation of primary amines to nitro compounds on dry silica gel (Keinan and Mazur, 1977) and in solution (Bachman and Strawn, 1968; Bailey et al., 1972). We do not detect any ions for the proposed nitroalkane end products of ozonized ODA or HDA. The $\mathrm{NO}_{2}^{-}$ion can arise from three sources: a) dissociative electron attachment of the nitroalkane, resulting in the formation of the $\mathrm{NO}_{2}^{-}$fragment ion; b) thermal decomposition of the nitroalkane (Nazin and Manelis, 1994) either in the flow reactor or c) in the volatilization process producing gas phase $\mathrm{NO}_{2}$ with subsequent ionization via associative electron attachment. To assay the viability of dissociative electron attachment forming $\mathrm{NO}_{2}^{-}$, we investigated the ionization of gas-phase 1-nitrohexane at $\sim 0 \mathrm{eV}$ ionization energy (Fig. 3). The base peak corresponding to $\mathrm{NO}_{2}^{-}$ and a very weak signal arising from the dissociative electron attachment ion corresponding to the loss of hydrogen $\left(\left[\mathrm{C}_{6} \mathrm{H}_{12} \mathrm{NO}_{2}\right]^{-}, 130 \mathrm{~m} / \mathrm{z}\right)$ are observed. We have made similar observations with other volatile nitroalkanes including 


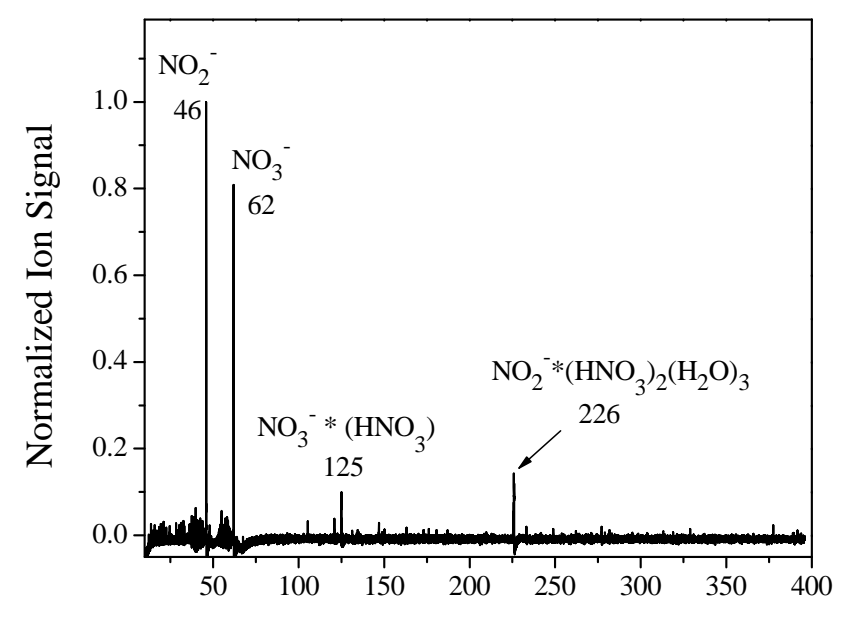

(a)

$\mathrm{m} / \mathrm{z}$

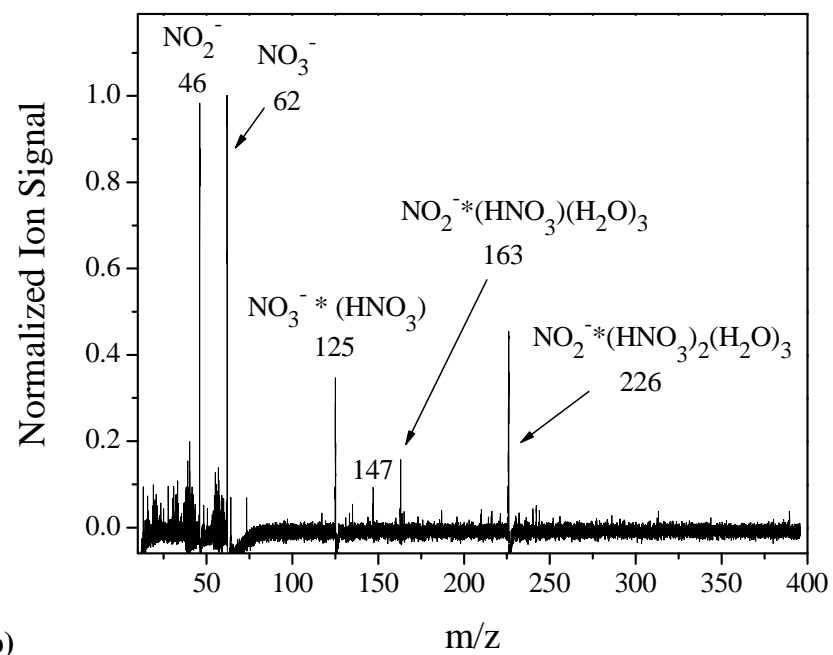

Fig. 1. PERCI mass spectrum of ozonized single component particles of ODA at $p_{\mathrm{O}_{3}}=(\mathbf{a}) 1 \times 10^{-4}$ atm and (b) $2 \times 10^{-4}$ atm. Reaction time was $5 \mathrm{~s}$.

nitrobutane and nitropropane, which further supports the viability of dissociative electron attachment forming $\mathrm{NO}_{2}^{-}$from nitroalkanes. Similarly, the formation of the $\mathrm{NO}_{2}^{-}$fragment with nitromethane (Modelli and Venuti, 2001; Gilman et al., 1983) and several nitrobenzene species (Modelli and Venuti, 2001; LaFranchi and Petrucci, 2004) has been reported with similar ionization energies. Thus it seems likely that nitroalkanes formed from progressive oxidation (Fig. 2) may be the source of $\mathrm{NO}_{2}^{-}$that occurs in the ionization process. It should also be noted that there is a weak $\mathrm{NO}_{3}^{-}$ion signal in the PERCI spectrum of 1-nitrohexane. This may be an experimental artifact arising from conversion of $\mathrm{NO}_{2}$ to $\mathrm{NO}_{3}$ on the metal surfaces (Ozensoy et al., 2005) in the ionization region of the mass spectrometer or from a disproportionation reaction (R1)(Sekimoto and Takayama, 2007):

$\mathrm{NO}_{2}^{-}+\mathrm{NO}_{2} \rightarrow \mathrm{NO}_{3}^{-}+\mathrm{NO}$

We have evidence that there is decomposition of the particulate nitroalkanes both in the flow reactor and in the volatilization process. The former route to $\mathrm{NO}_{2}$ formation is supported by the strong $\mathrm{NO}_{2}^{-}$signal evident from ozonized particles deposited on the Nichrome filament before heating the wire. Secondly, as shown in Fig. 1, the $\mathrm{NO}_{3}^{-}$ion signal increases with ozone exposure, indicating that $\mathrm{NO}_{2}$ is liberated from the nitroalkanes in the flow reactor at the particles' surface or near surface and then oxidized according to the reaction (Finlayson-Pitts and Pitts Jr., 1999):

$\mathrm{NO}_{2}+\mathrm{O}_{3} \stackrel{\text { particle }}{\longrightarrow} \mathrm{NO}_{3}+\mathrm{O}_{2}$.

In the ozonolysis of particle bound amines, the $\mathrm{NO}_{3}^{-}$ion signal was strong for all exposures, but increased in intensity with increasing ozone exposure. There are several possible pathways that we believe exist in forming this ion including: a) disproportionation ( $\mathrm{R} 1)$; b) oxidation of $\mathrm{NO}_{2}$ by ozone (R2); and c) conversion of $\mathrm{NO}_{2}$ to $\mathrm{NO}_{3}^{-}$via a surface reaction (Ozensoy et al., 2005) that occurs in the volatilization process. Reaction (R2) is likely the most important pathway to $\mathrm{NO}_{3}^{-}$due to the concomitant increase in its ion signal intensity with increasing ozone exposure, as well as the very weak ion signal for $\mathrm{NO}_{3}$ in the gas phase studies that suggest Reaction (R1) and surface processes are minor pathways. It should be noted that large molecular electron affinities (EA) of $\mathrm{NO}_{2}$ (EA $2.25-2.38 \mathrm{eV}$ (Ervin et al., 1988), and references therein) and $\mathrm{NO}_{3}(\mathrm{EA}=3.92 \mathrm{eV}$ (Hirokawa et al., 2001), and references therein) may translate into large $0 \mathrm{eV}$ electron capture cross sections, thereby increasing our sensitivity to these analytes; however, we cannot discount the possibility that there is a high conversion of the amines to the nitroalkanes at the particles surface upon ozone exposure.

There are also medium intensity ion signals in the ozonized ODA and HDA spectra at 125 and $226 \mathrm{~m} / \mathrm{z}$. These ion signals also increase with ozone exposure. We assign the $125 \mathrm{~m} / \mathrm{z}$ ion signal to $\mathrm{NO}_{3}^{-} \bullet\left(\mathrm{HNO}_{3}\right)$. This ion is the core ion of the series $\mathrm{NO}_{3}^{-} \bullet\left(\mathrm{HNO}_{3}\right)_{n}\left(\mathrm{H}_{2} \mathrm{O}\right)_{m}$, which is the most important negative ion family in the atmospheric at ground level (Heitmann and Arnold, 1983; Perkins and Eisele, 1984). This ion may be formed from the following reaction sequence with the rapid ion-molecule association reaction (Fehsenfeld et al., 1975) being the final step:

$$
\begin{aligned}
& 2 \mathrm{NO}_{2}+\mathrm{H}_{2} \mathrm{O} \stackrel{\text { particle }}{\longrightarrow} \mathrm{HONO}+\mathrm{HNO}_{3} \\
& \mathrm{HNO}_{3}+\mathrm{H}_{2} \mathrm{O} \stackrel{\text { particle }}{\longrightarrow} \mathrm{NO}_{3}^{-}+\mathrm{H}_{3} \mathrm{O}^{+} \\
& \mathrm{NO}_{3}^{-}+\mathrm{HNO}_{3} \stackrel{\text { particle }}{\longrightarrow} \mathrm{NO}_{3}^{-} \bullet \mathrm{HNO}_{3}
\end{aligned}
$$




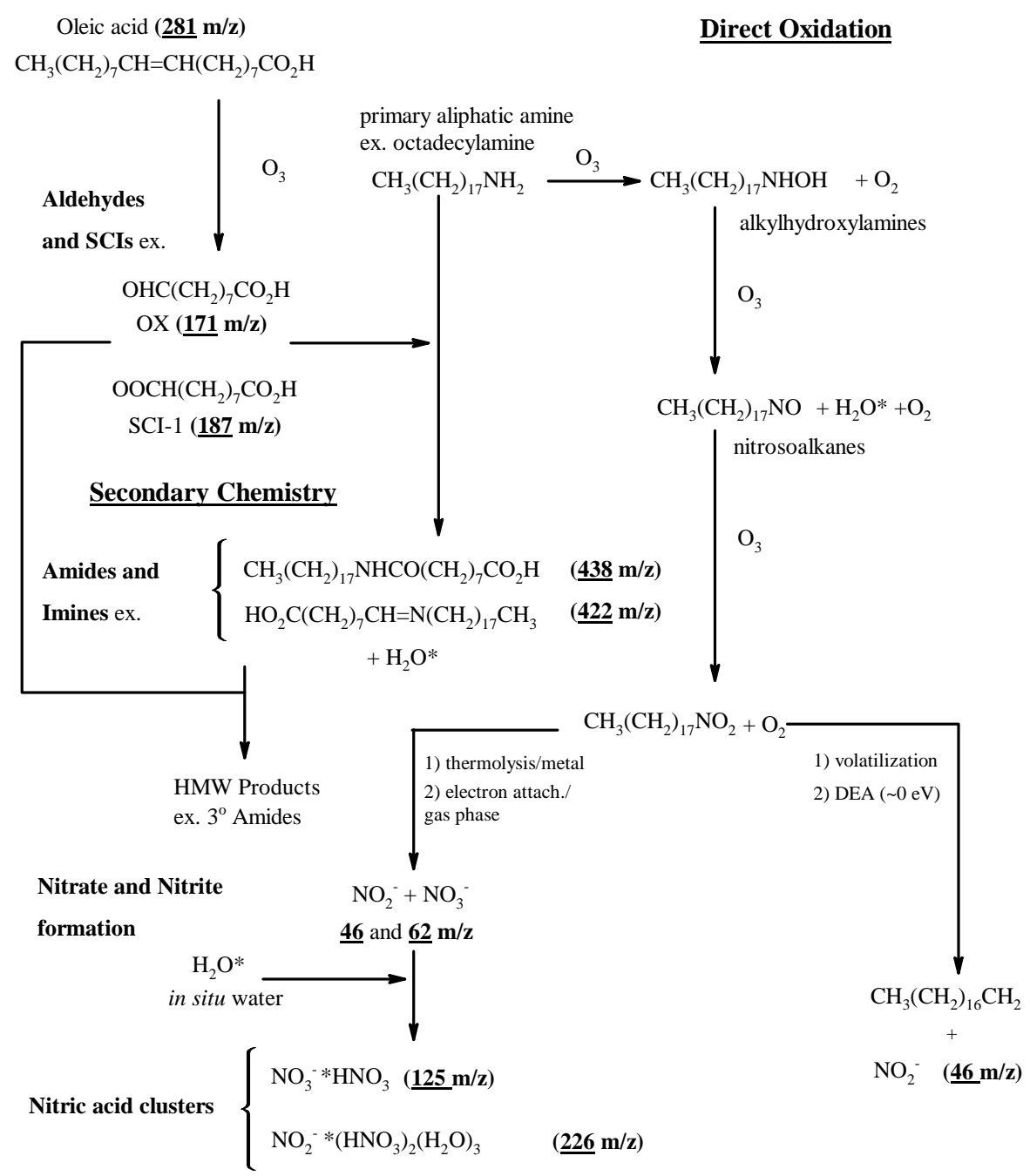

Fig. 2. Pathways of direct oxidation and secondary reactivity with ozonized amines (ODA shown as an example). The pathway labeled Direct Oxidation occurs with both single component particulate amines and in mixed particles with the amine + OL. All products observed are underlined. The direct oxidation products are identical with ozonized HDA. The amides and imines that form in the HDA + OL mixed particles are similar in structure to those indicated, except 28 u lower in mass. OX denotes 9-oxononanoic acid.

Reaction (R3a) is the overall stoichiometry of the wellknown surface reaction for the hydrolysis of $\mathrm{NO}_{2}$ (FinlaysonPitts et al., 2003; Pitts Jr et al., 1984) that generates both gas phase nitrous acid (HONO) and nitric acid (Finlayson-Pitts et al., 2003). This entire reaction sequence could occur on either the surface of the particle and/or on the surface of the deposited particulate matter on the vaporization coil. The $125 \mathrm{~m} / \mathrm{z}$ ion is observed evolving both before and during the volatilization process, indicating that formation of this ion is not exclusively a result of the thermal vaporization process used in generating the gas phase molecules requisite for ionization in PERCI AMS. This observation supports that at least a fraction of $\mathrm{NO}_{3}^{-} \mathrm{HNO}_{3}$ is formed on the surface of the particles.
An alternate route to $\mathrm{NO}_{3}^{-} \mathrm{HNO}_{3}$ is via $\mathrm{N}_{2} \mathrm{O}_{5}$, which could accumulate on the surface of the particles. This route follows Reaction (R2) and results in the formation of nitric acid on the surface of the particle:

$$
\begin{aligned}
& \mathrm{NO}_{2}+\mathrm{NO}_{3} \stackrel{\text { particle }}{\longrightarrow} \mathrm{N}_{2} \mathrm{O}_{5} \\
& \mathrm{~N}_{2} \mathrm{O}_{5}+\mathrm{H}_{2} \mathrm{O} \stackrel{\text { particle }}{\longrightarrow} 2 \mathrm{HNO}_{3} .
\end{aligned}
$$

This reaction sequence is based on the premise that a fraction of $\mathrm{NO}_{2}$ is generated at or near the surface of the particle as a result of decomposition of the nitroalkane that formed by the mechanism of progressive oxidation. The $\mathrm{NO}_{2}$ then reacts with ozone to give $\mathrm{NO}_{3}$ (DeMore et al., 1997). The $\mathrm{NO}_{3}$ subsequently reacts with $\mathrm{NO}_{2}$ to give $\mathrm{N}_{2} \mathrm{O}_{5}$ (DeMore et al., 1997), which hydrolyzes in the presence of water, yielding 


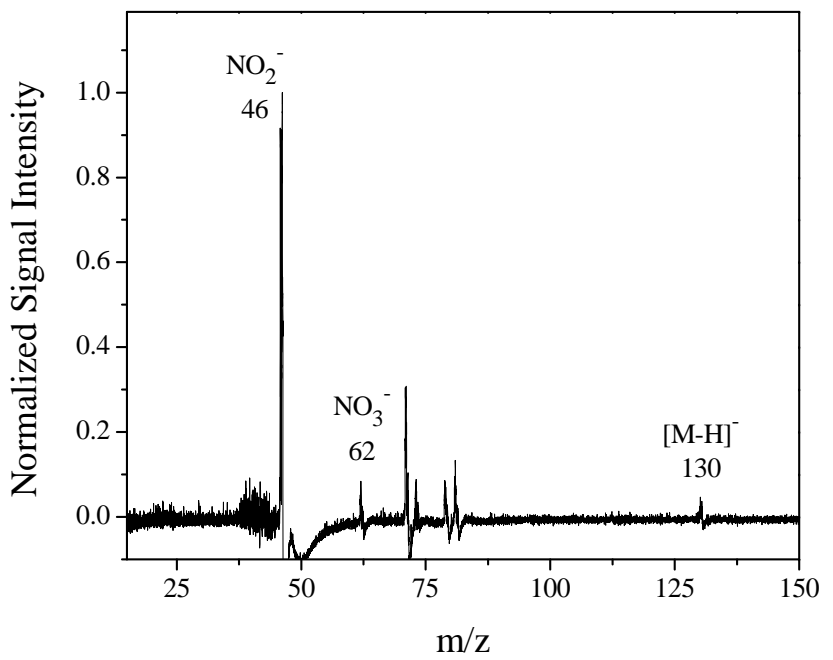

Fig. 3. PERCI mass spectrum of 1-nitrohexane introduced into the PERCI AMS as a gas $\left(p=2 \times 10^{-5}\right.$ atm). Photoelectron energy was $\sim 0 \mathrm{eV}$.

nitric acid. This last step (i.e. Reaction (R4b) is akin to the hydrolysis of $\mathrm{N}_{2} \mathrm{O}_{5}$ that has been described previously on aerosols (Wahner et al., 1998). As shown in Fig. 2, the reactant water in Reaction (R4b) forms on the surface of the particle via the oxidation of the intermediate alkylhydroxylamine to the nitrosoalkane. The resulting nitric acid could then proceed by Reaction (R3c) to give $\mathrm{NO}_{3}^{-} \bullet \mathrm{HNO}_{3}$.

The $226 \mathrm{~m} / \mathrm{z}$ ion does not correspond with any anion cluster in the $\mathrm{NO}_{3}^{-} \bullet\left(\mathrm{HNO}_{3}\right)_{n}\left(\mathrm{H}_{2} \mathrm{O}\right)_{m}$ series, and to the best of our knowledge, it is not a commonly observed ion containing any combination of $\mathrm{H}, \mathrm{N}$, and $\mathrm{O}$. This ion is observed not only in the ozonolysis of ODA and HDA, but also for ozonized octylamine $(129 \mathrm{u})$ and lysine $(146 \mathrm{u})$, indicating that it is not an ion directly arising from the fragmentation of the amine (or amino acid) or their corresponding nitrocompounds. We tentatively assign this ion signal to the cluster $\mathrm{NO}_{2}^{-} \bullet\left(\mathrm{HNO}_{3}\right)_{2}\left(\mathrm{H}_{2} \mathrm{O}\right)_{3}$. Although, to our knowledge, this ion has not been observed, we hypothesize that it could originate from $\mathrm{HNO}_{3} \bullet \mathrm{NO}_{2}$. This species has recently been detected in the attenuated total reflectance FTIR studies of the heterogeneous hydrolysis of $\mathrm{NO}_{2}$ (Ramazan et al., 2006). A small ion signal at $163 \mathrm{~m} / \mathrm{z}$ is also evident in the PERCI spectrum that becomes more intense with increasing ozone exposure. We tentatively assign this to another member of this proposed ion series, $\mathrm{NO}_{2}^{-} \bullet\left(\mathrm{HNO}_{3}\right)\left(\mathrm{H}_{2} \mathrm{O}\right)_{3}$. Even at high ozone exposures, the $163 \mathrm{~m} / \mathrm{z}$ ion signal is relatively weak compared to the four signals discussed previously (i.e. 46, 62,125 , and $226 \mathrm{~m} / \mathrm{z}$ ) for the ozonized single-component amine particles. For simplicity, in the remainder of this work we will refer to the 4 strongest ions of the ozonized singlecomponent amine particles as the "characteristic ions of the amine".
Table 1. High molecular weight, nitrogen containing products formed in the heterogeneous ozonolysis of mixed ODA/OL particles and their corresponding assignments. The corresponding ions, with masses $28 \mathrm{u}$ lower, were observed also in the HDA/OL system. OX denotes 9-oxononanoic acid.

\begin{tabular}{|c|c|c|}
\hline Compound & Chemical Product & Comments \\
\hline 1 & $\mathrm{CH}_{3}\left(\mathrm{CH}_{2}\right)_{17} \mathrm{NHCO}\left(\mathrm{CH}_{2}\right)_{7} \mathrm{CHO}$ & $\begin{array}{l}422 \mathrm{~m} / \mathrm{z} \text {, Secondary amide, } \\
\mathrm{ODA}+\mathrm{OX}-\mathrm{H}_{2} \mathrm{O}\end{array}$ \\
\hline 2 & $\mathrm{CH}_{3}\left(\mathrm{CH}_{2}\right)_{17} \mathrm{~N}=\mathrm{CH}\left(\mathrm{CH}_{2}\right)_{7} \mathrm{CO}_{2} \mathrm{H}$ & $422 \mathrm{~m} / \mathrm{z}$, imine, $\mathrm{ODA}+\mathrm{OX}-\mathrm{H}_{2} \mathrm{O}$ \\
\hline 3 & $\mathrm{CH}_{3}\left(\mathrm{CH}_{2}\right)_{17} \mathrm{NHCO}\left(\mathrm{CH}_{2}\right)_{7} \mathrm{CO}_{2} \mathrm{H}$ & $\begin{array}{l}438 \mathrm{~m} / \mathrm{z} \text {, secondary amide, } \\
\mathrm{ODA}+\mathrm{SCI}-1-\mathrm{H}_{2} \mathrm{O}\end{array}$ \\
\hline 4 & $\mathrm{CH}_{3}\left(\mathrm{CH}_{2}\right)_{17} \mathrm{~N}\left(\mathrm{CO}\left(\mathrm{CH}_{2}\right)_{7} \mathrm{CHO}\right)_{2}$ & $\begin{array}{l}576 \mathrm{~m} / \mathrm{z} \text {, tertiary amide, ODA } \\
+2 \mathrm{OX}-2 \mathrm{H}_{2} \mathrm{O}\end{array}$ \\
\hline 5 & $\left.\right|_{\mathrm{CO}}\left(\mathrm{CH}_{2}\right)_{7} \mathrm{CO}_{2} \mathrm{H}$ & $\begin{array}{l}592 \mathrm{~m} / \mathrm{z} \text { tertiary amide, ODA } \\
+\mathrm{OX}+\mathrm{SCI}-1-2 \mathrm{H}_{2} \mathrm{O}\end{array}$ \\
\hline 6 & $\mathrm{CH}_{3}\left(\mathrm{CH}_{2}\right)_{17} \mathrm{~N}\left(\mathrm{CO}\left(\mathrm{CH}_{2}\right)_{7} \mathrm{CO}_{2} \mathrm{H}\right)_{2}$ & $\begin{array}{l}608 \mathrm{~m} / \mathrm{z} \text { tertiary amide, ODA } \\
+2 \mathrm{SCI}-1-2 \mathrm{H}_{2} \mathrm{O}\end{array}$ \\
\hline
\end{tabular}

Nitrite and nitrate ions were measured in all singlecomponent particles of ODA and HDA and in mixed particles containing the amines and well as DOS as the second component. The DOS + amine PERCI spectrum is relatively simple with three of the ions having been determined to be unique to the ester: the dissociative electron attachment ion ([DOS-H $]^{-}$) at $425 \mathrm{~m} / \mathrm{z}$, and two fragments 295 and $313 \mathrm{~m} / \mathrm{z}$. These ions probably arise from the fragmentation of the ester linkage (Zahardis et al., 2006b), with $313 \mathrm{~m} / \mathrm{z}$ assigned to $\quad\left[\mathrm{CH}_{3}\left(\mathrm{CH}_{2}\right)_{3} \mathrm{CH}\left(\mathrm{CH}_{2} \mathrm{CH}_{3}\right) \mathrm{CH}_{2} \mathrm{OCO}\left(\mathrm{CH}_{2}\right)_{8} \mathrm{COO}\right]^{-}$. The $295 \mathrm{~m} / \mathrm{z}$ ion is tentatively assigned to $\left[\mathrm{CH}_{3}\left(\mathrm{CH}_{2}\right)_{3} \mathrm{CH}\left(\mathrm{CH}_{2} \mathrm{CH}_{3}\right) \mathrm{CH}_{2} \mathrm{OCO}\left(\mathrm{CH}_{2}\right)_{6} \mathrm{CH}=\mathrm{CHCO}\right]^{-}$ or similar dehydration product of the $313 \mathrm{~m} / \mathrm{z}$ fragment. There was no measureable difference in the PERCI mass spectrum of pure DOS particles upon ozonolysis. The four characteristic ions of the amine were also observed for both ODA and HDA upon ozonolysis of the mixed particles containing DOS. The PERCI mass spectrum of ODA (or HDA) + OL, on the other hand, is far more complex.

\subsection{Ozonolysis of ODA (HDA) in mixed particulate matter - overview}

DOS and other related high molecular weight esters (Ziemann, 2005; Mochida et al., 2006) employed in studies of heterogeneous ozonolysis are used often as controls because they are not a source of Criegee intermediates (CI). The reactivity of SCI with ODA and HDA was a key feature in the oxidative processing of these mixed particles, especially in the formation of high molecular weight compounds. Ozone concentrations were varied from the same order of magnitude as typical summertime maximum daily concentrations in a suburban-urban troposphere 
(100-400 ppb i.e. $1-4 \times 10^{-7}$ atm) (National Research Council, 1991) to very high concentrations: up to $\sim 10^{-3} \mathrm{~atm}$. Assaying the effects of high ozone concentrations on mixed particles helped in elucidating the mechanisms of oxidation. Secondarily, the products formed under high oxidative stress may be similar to products formed when particulate matter with high amine and lipid content (i.e. meat cooking aerosols) is subjected to both thermal stress and enhanced ozone levels associated with the urban troposphere.

For conciseness, the ensuing discussion places emphasis on comparing the low ozone exposure regime (which we define as $10^{-6}-10^{-7} \mathrm{~atm}$ ozone for $\sim 17 \mathrm{~s}$ ) to the very high ozone exposure regime ( $\geq 10^{-3} \mathrm{~atm}$ for $\left.\sim 17 \mathrm{~s}\right)$.

3.3 Ozonolysis of ODA (HDA) + OL in mixed particles: products assignments for low ozone exposure

Figure 4a,b compare PERCI mass spectra for the ozonolysis of mixed ODA/OL particles at $3 \times 10^{-7}$ atm and $2 \times 10^{-3} \mathrm{~atm}$ ozone, respectively, for a $17 \mathrm{~s}$ reaction time. Of the four expected lower molecular weight products of the heterogeneous ozonolysis of OL (i.e., azelaic acid (188 u), 9-oxononanoic acid $(172 \mathrm{u})$, nonanoic acid $(158 \mathrm{u})$, and nonanal (142u) (Zahardis and Petrucci, 2007)), only azelaic acid $(187 \mathrm{~m} / \mathrm{z})$ is observed for the mixed particles (ODA (HDA) + OL), at very low exposure. On the other hand, all 4 characteristic ions expected from reaction of the aliphatic amine $(46,62,125$, and $226 \mathrm{~m} / \mathrm{z})$, as well as the minor ion at $163 \mathrm{~m} / \mathrm{z}$ are observed.

At ozone exposures of $\sim 3 \times 10^{-7}$ atm (17 s) and higher in the ODA + OL system, we also observe ions at 422 and $438 \mathrm{~m} / \mathrm{z}$. The $438 \mathrm{~m} / \mathrm{z}$ ion is assigned to the amide that may be formed by several pathways, including reaction of the SCI-I (cf. Fig. 2) with ODA. The $422 \mathrm{~m} / \mathrm{z}$ ion could arise from a $423 \mathrm{u}$ product that is either an amide or an imine (i.e. Schiff base). The amide could be formed from ODA and 9-oxononanoic acid, with the amine reacting at the carboxyl position. The imine (i.e. Schiff base), 9-(octadecylimino) nonanoic acid, could be a product of the reaction of ODA with the aldehyde functionality of 9-oxononanoic acid. This ion is nominally one mass unit lower than the mass of the proposed ion indicating dissociative electron attachment ionization via the loss of hydrogen. These assignments are supported by ion signals measured at 394 and $410 \mathrm{~m} / \mathrm{z}$ in the $\mathrm{HDA}+\mathrm{OL}$ mixed particles $\left(p_{\mathrm{O}_{3}}=3 \times 10^{-7}\right.$ atm and $17 \mathrm{~s}$ reaction time). These higher molecular weight signals are assigned to the amides and imine corresponding with reaction of HDA with 9-oxononanoic acid and SCI-I respectively. These ions are not observed at lower concentrations of ozone in the ODA (HDA) + OL reaction system. These ion signals are also not observed under any conditions of ozone exposure for ODA or HDA in DOS. It should be noted that we do not observe any dissociative electron attachment ion for the amides that could be the product of the reaction of the 158 u SCI (SCI-2, i.e. $\left.\mathrm{OOCH}\left(\mathrm{CH}_{2}\right)_{7} \mathrm{CH}_{3}\right)$ with ODA or
HDA. These amides would have an alkyl end, unlike the amides arising from the reaction of SCI-1 which have a carboxyl group functionality. It is likely that SCI-2 does form amides with these amines, but they are not ionized to any significant extent with $\sim 0 \mathrm{eV}$ electrons, as is the case with all organic acids (LaFranchi and Petrucci, 2006; LaFranchi et al., 2004; Zahardis et al., 2005, 2006c) investigated to date. The high molecular weight, nitrogen-containing products measured and their corresponding assignments are summarized in Table 1.

\subsection{Ozonolysis of ODA (HDA) + OL in mixed particles:} products assignments for high ozone exposure

The mass spectrum of products arising from heterogeneous reaction ODA(HDA) + OL aerosols with $\sim 2 \times 10^{-3} \mathrm{~atm}$ ozone at $\sim 17 \mathrm{~s}$ reaction time (Fig. $4 \mathrm{~b}$ ) shows the four characteristic ions of the aliphatic amine (i.e. 46, 62, 125, and $226 \mathrm{~m} / \mathrm{z}$ ) in addition to two distinct regions of high molecular weight products, mainly the dissociative electron attachment ions of secondary and tertiary amides formed via the secondary reactions of ozonolysis. The four classical products of OL ozonolysis are also evident in both the ODA and HDA mixed particles. Interestingly, the OL molecular ion at $281 \mathrm{~m} / \mathrm{z}$ is one of the strongest ion signals in the PERCI mass spectrum for the ozonolysis of ODA + OL aerosols (Fig. 4), but only a very weak signal in the HDA + OL system at this same exposure (not shown). Under identical exposure conditions, the OL molecular ion was not observed in the reaction of pure OL particles. Moreover, for the pure OL particles, no OL molecular ion was observed for any ozone concentration above $1 \times 10^{-4}$ atm ozone for $\sim 17 \mathrm{~s}$ reaction time. We believe these unanticipated effects (i.e. the retention of OL in the ODA + OL reaction system at this very high ozone exposure) originate from surface or near surface reactions that produce high molecular weight secondary and tertiary amides. These surface active species, in turn, may impede the diffusion of ozone into the particle and limit the diffusion of OL to the surface, thereby effectively shutting down the ozonolysis of OL.

3.5 A mechanistic account for the formation of the observed products in the ozonized mixed particles

A detailed account of the heterogeneous ozonolysis of OL has recently been published (Zahardis and Petrucci, 2007) and many mechanistic depictions are available in the literature (Ziemann, 2005; Zahardis et al., 2005; Hung et al., 2005; Reynolds et al., 2006; Katrib et al., 2004). The three main steps of ozonolysis of oleic acid are in accord with established solution phase chemistry (Bailey, 1978):

- Step 1: formation of the primary ozonide (i.e. 1, 2, 3trioxolane) 


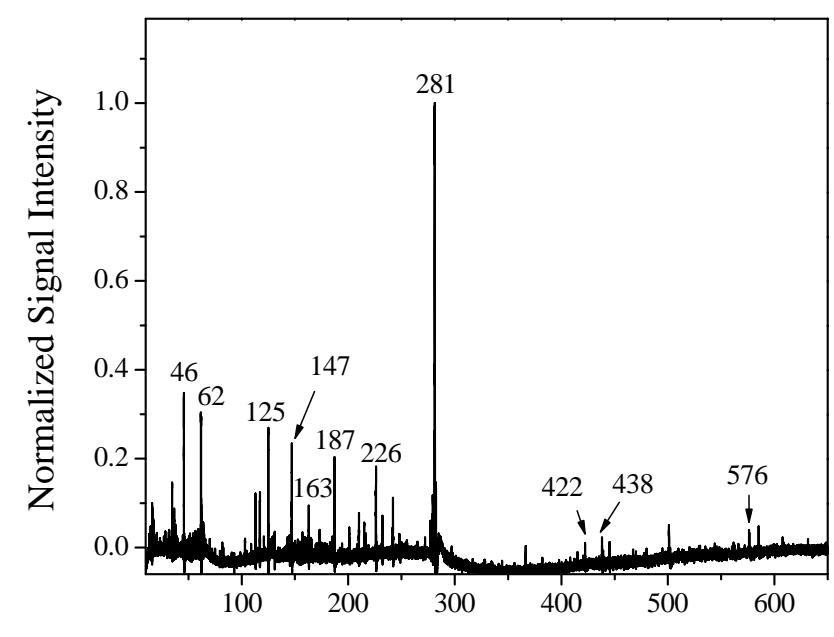

(a)

$\mathrm{m} / \mathrm{z}$

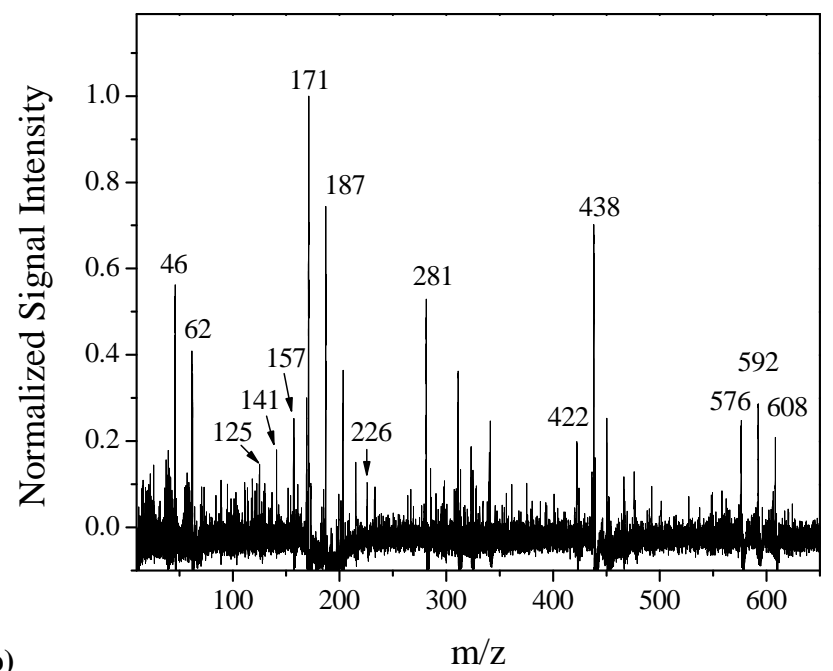

(b)

$\mathrm{m} / \mathrm{z}$

Fig. 4. PERCI mass spectrum of ozonized mixed particles of ODA + OL at $p_{\mathrm{O}_{3}}=$ (a) $3 \times 10^{-7}$ atm and (b) $2 \times 10^{-3}$ atm. Reaction time was $17 \mathrm{~s}$. Mole fractions, $\chi$, were $\chi_{\mathrm{ODA}}=0.41$ and $\chi_{\mathrm{OL}}=0.59$.

- Step 2: decomposition of the primary ozonides to aldehydes and excited Criegee intermediates, which in solution rapidly stabilize to SCI

- Step 3: recombination of the SCI and aldehyde to form secondary ozonides (and other reactions including: intermolecular reactions to form diperoxides, or reactions with acids e.g. OL, to give $\alpha$-acyloxyalkyl hydroperoxides)

There exists considerable debate concerning the formation of azelaic acid and nonanoic acid and their relationship with SCI-1 and SCI-2 (Zahardis and Petrucci, 2007). It has been suggested that these two acids are formed from isomerization of SCI-1 and SCI-2 (i.e. $\mathrm{OOCH}\left(\mathrm{CH}_{2}\right)_{7} \mathrm{CO}_{2} \mathrm{H}$ and $\left.\mathrm{OOCH}\left(\mathrm{CH}_{2}\right)_{7} \mathrm{CH} 3\right)$ (Ziemann, 2005; Zahardis et al., 2005; Hearn and Smith, 2004; Hung et al., 2005) or, conversely, form as decomposition products of the secondary ozonides and other peroxides as higher generation reaction products (Martin, 2006b, a). Recent mass spectral evidence (Reynolds et al., 2006) suggests that fragmentation occurring in the ionization process of high molecular weight peroxides may also contribute to the evolution of ions corresponding to these acids. A more extensive discussion of the formation of these acids as well and other mechanistic features of this reaction system are beyond the scope of this report and have been covered elsewhere (Zahardis and Petrucci, 2007).

The amide 9-(octadecylamino)-9-oxononanoic acid ( $439 \mathrm{u}, 438 \mathrm{~m} / \mathrm{z})$ may be formed by several different routes in the ozonolysis of ODA + OL. Route 1 is the wellestablished route via acylation of an amine by a carboxylic acid (i.e. azelaic acid) (Satchell, 1963), which we believe to be a minor pathway in the formation of amides in these heterogeneous reaction systems. Route 2 involves reaction of the amine (ODA) with SCI-1 (Fig. 5a), while Route 3 may result in amide formation via reaction of ODA with a secondary ozonide (Fig. 5b). Similar routes exist for the formation of 9-(hexadecylamino)-9-oxononanoic acid $(411 \mathrm{u}, 410 \mathrm{~m} / \mathrm{z})$ in the HDA + OL reaction system.

We tested the relative importance of Routes 2 and 3 by preparing mixed particles with a very high concentration of azelaic acid. These mixed particles contained the inert matrix DOS, which like other esters does not undergo ozonolysis or react with SCI (Mochida et al., 2006; Ziemann, 2005). Figure 6 compares the evolution of the $438 \mathrm{~m} / \mathrm{z}$ amide between the azelaic acid + ODA + DOS and ODA + OL heterogeneous reaction systems, at four ozone concentrations. The $438 \mathrm{~m} / \mathrm{z}$ ion was either not observed or was a very weak signal in the azelaic acid + ODA + DOS mixed particles under all exposure conditions. Further, no other ion signals corresponding to amides were observed in the azelaic acid + ODA + DOS heterogeneous reaction system. On the other hand, the $438 \mathrm{~m} / \mathrm{z}$ amide was produced in significant amounts in the ODA + OL reaction system (Fig. 6) and was directly proportional to the ion signal for azelaic acid generated in situ to the ODA/OL particle. The direct proportionality of amide formation with azelaic acid does not contradict the aforementioned result because the azelaic acid signal we measure is directly proportional to the in situ generated SCI-1 and likely directly proportional as well with the secondary ozonides in the system that can decompose to the acid. Our results indicate it is the reactivity of these chemical classes (i.e. SCI and secondary ozonides) with the amines that constitute the main routes to amides; however, with the extant data there is no way to estimate the relative importance of Route 2 vs. 3 .

The observation that the classic acylation route to the amide is a minor pathway suggests that the $422(394) \mathrm{m} / \mathrm{z}$ 


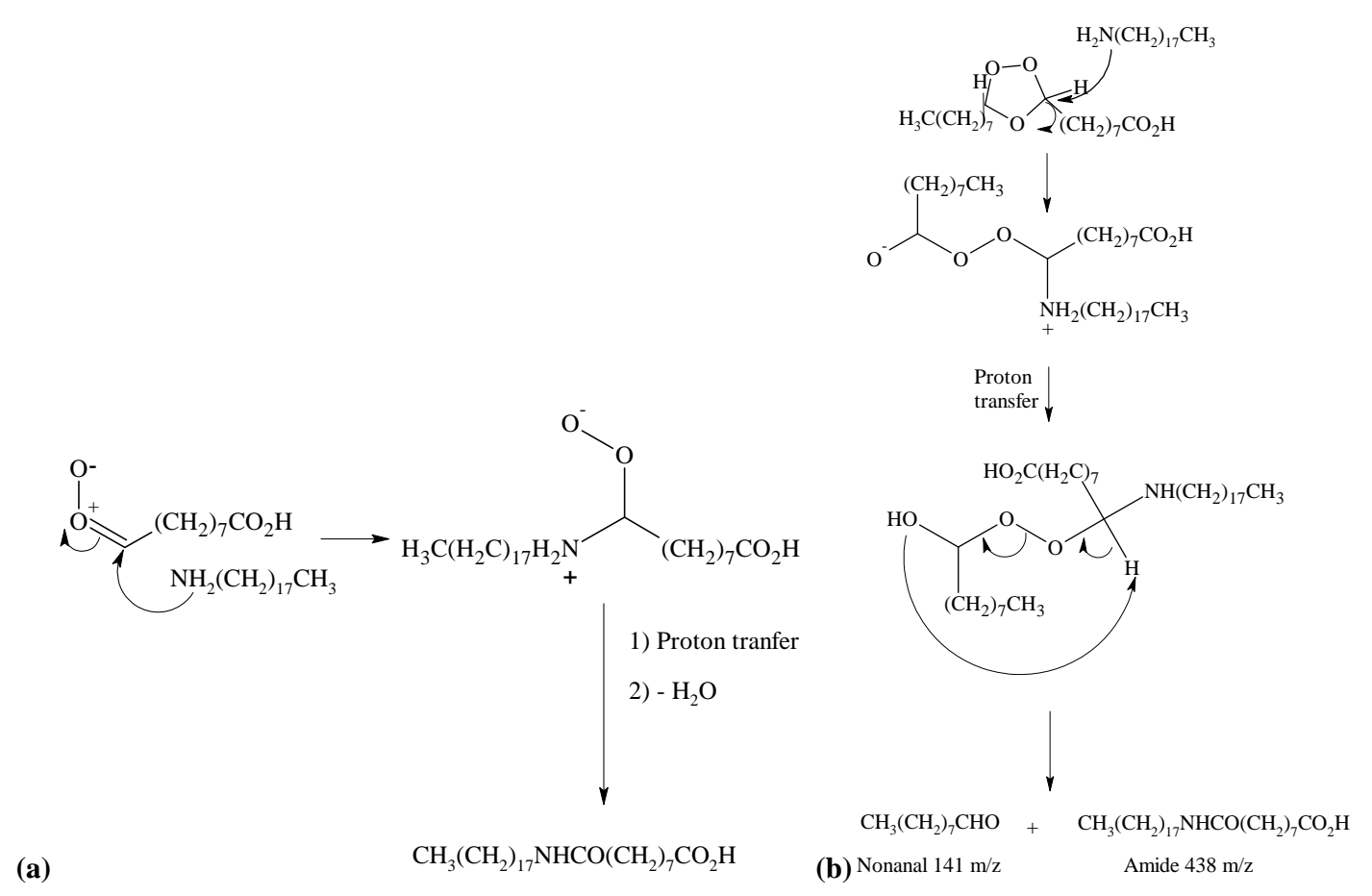

Fig. 5. Proposed mechanisms for observed amide formation via reactions of amines with products of ozonolysis of OL. Amide formation via reaction of (a) ODA with an SCI (shown SCI-1) and (b) ODA and a secondary ozonide. Similar reactions for HDA are discussed in text.

product observed in the ODA (HDA) + OL reaction system arises from the reaction of the amine with the aldehyde moiety of 9-oxononanoic acid, rather than the carboxyl group, i.e. the $422(394) \mathrm{m} / \mathrm{z}$ products are most likely imines. The formation of imine products from the reaction of aldehydes and ketones with primary amines has been shown to have a rapid rate of reaction (Hine et al., 1973; Hine and Via, 1972). For example, the imine forming reactions between methylamine and $n$-propylamine with isobutyraldehyde are described by second order rate constants $\left(35^{\circ} \mathrm{C}\right)$ of 53 and $50 \mathrm{M}^{-1} \mathrm{~s}^{-1}$, respectively (Hine and Via, 1972). It should be noted that these kinetic studies were done in aqueous solutions (Hine et al., 1973; Hine and Via, 1972), so caution should be taken in directly comparing the results of these studies with our particle-based flow reactor experiments, especially since these particles were initially anhydrous, with water being formed by the in situ oxidative processing of the amines with ozone (see Fig. 2).

\subsection{The formation of a solid or viscous surface layer}

The OL ion signal was measured for three types of ozonized particles as a function of ozone exposure: (neat) OL, ODA + OL, and HDA + OL (Fig. 7). The OL ion signal in neat particles and mixed particles of HDA + OL follows an exponential decay at low ozone exposures. Neither of these particles shows a measurable OL signal at ozone exposures above $1 \times 10^{-4}$ atm at $17 \mathrm{~s}$ reaction time. In the ODA $+\mathrm{OL}$ reaction system, on the other hand, OL decays exponentially initially up to an ozone exposure of $1 \times 10^{-4}$ atm but then re-emerges at very high exposures $\left(\geq 6 \times 10^{-4}\right.$ atm for $17 \mathrm{~s}$ reaction). This suggests that at a critical level of ozone exposure, the particles develop a solid or highly viscous liquid surface layer that impedes the diffusion of ozone into the particle. Similar effects have been observed in the formation of solid surface layers with ozonized myristic acid + OL particles (Nash et al., 2006). Figure 8 compares the PERCI ion signal of OL $(281 \mathrm{~m} / \mathrm{z})$ to the integrated ion signal of the 5 high molecular weight products $(422,438,576$, 592 and $608 \mathrm{~m} / \mathrm{z}$ ). The ion signal of the $438 \mathrm{~m} / \mathrm{z}$ secondary amide increases rapidly for ozone exposures in the range 0 to $1 \times 10^{-4} \mathrm{~atm}$ and $17 \mathrm{~s}$ reaction time. Furthermore, no appreciable increase in intensity is measured at higher exposures. In comparison, the $422 \mathrm{~m} / \mathrm{z}$ amide/imine and the three high molecular weight tertiary amides show less rapid initial increase in their ion intensity with a linear, generally monotonic, increase in intensity at exposures above $1 \times 10^{-4} \mathrm{~atm}$ $\mathrm{O}_{3}$. The total amide/imine ion intensity rapidly rises for a $17 \mathrm{~s}$ reaction with $0-1 \times 10^{-4}$ atm $\mathrm{O}_{3}$. At higher exposures, a linear, monotonic increase is observed, with the exception of the $1 \times 10^{-3}$ atm $\mathrm{O}_{3}$ exposure, where there is a slight decrease in the PERCI ion intensity. From these data, we cannot definitively assign any particular imine or amide with the formation of a solid or viscous liquid layer that impedes the diffusion of ozone into the particle, although it appears that 


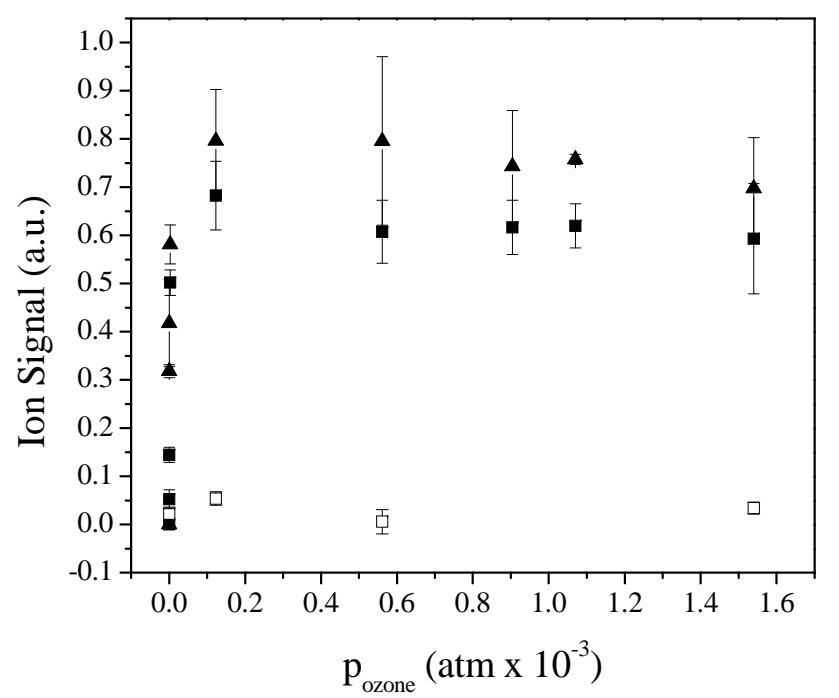

Fig. 6. Formation of a $(\boldsymbol{\square})$ secondary amide $(438 \mathrm{~m} / \mathrm{z})$ and $(\boldsymbol{\Lambda})$ SCII $(187 \mathrm{~m} / \mathrm{z})$ in ODA/OL mixed particles $\left(\chi_{\mathrm{OL}}=0.59, \chi_{\mathrm{ODA}}=0.41\right)$ compared to formation of $(\square)$ secondary amide $(438 \mathrm{~m} / \mathrm{z})$ in azelaic acid/ODA/DOS mixed particles $\left(\chi_{\text {azelaic }}=0.22, \chi_{\mathrm{ODA}}=0.24\right.$, $\chi_{\text {DOS }}=0.54$ ) with no possible concurrent formation of SCI-I in particle. Error bars indicate one standard deviation.

the best correlation is between the total amide/imine content and the formation of this layer.

\section{Conclusions and implications}

The experiments described in this work have lead to several significant observations for the ozonolysis of particle bound amines.

1. Our observation of a strong ion signal corresponding to nitrogen dioxide indicates nitroalkanes are generated from primary aliphatic particulate amines by the mechanism of progressive oxidation (Bachman and Strawn, 1968; Bailey et al., 1972; Keinan and Mazur, 1977). This is in accord with the ozonolysis of amines in solution (Bachman and Strawn, 1968; Bailey et al., 1972) and on dried surfaces (Keinan and Mazur, 1977) rather than in the gas phase (Tuazon et al., 1994; Murphy et al., 2007; Angelino et al., 2001), where large yields of aldehydes would be anticipated (Tuazon et al., 1994). We do not observe any aldehyde or other oxygenate signal in the ozonolysis of single component particles of amines under any conditions of ozone exposure. This probably stems from the stabilization of either the amine oxide or alkylhydroxylamine (Fig. 2) early in the reaction sequence in the ozonolysis of the particulate amines. Stabilization would favor the formation of the nitrosamine, which is subsequently oxidized to the nitroalkane. This is quite different than in the gas phase, where the excited amine oxide or alkylhydroxylamine intermediate

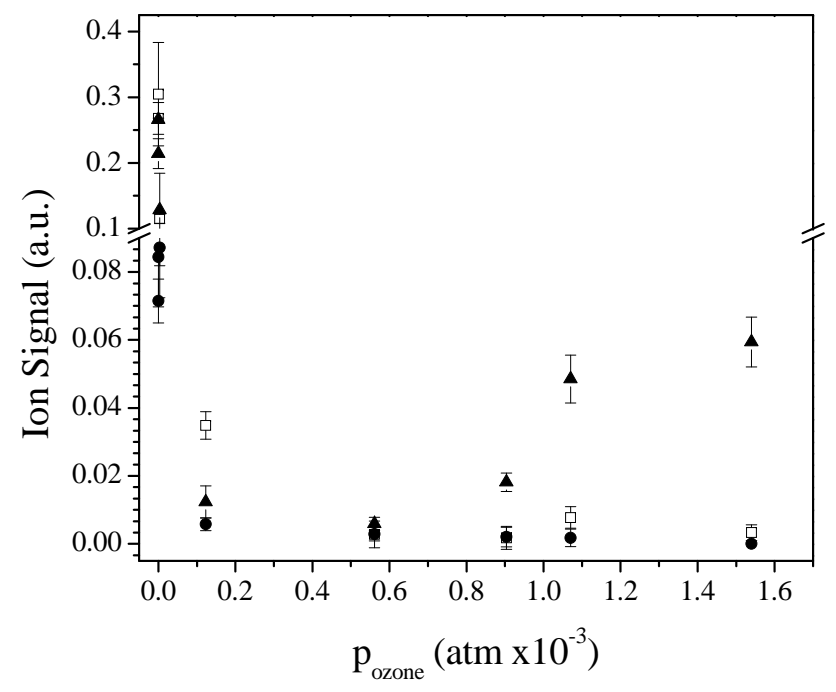

Fig. 7. Comparison of OL decay for three particle types: $(\bullet)$ neat OL particles, $(\boldsymbol{\Delta})$ ODA/OL mixed particles, and ( $\square$ ) HDA/OL mixed particles. Mole fractions, $\chi$, were $\chi \mathrm{ODA} / \mathrm{HDA}=0.41$ and $\chi_{\mathrm{OL}}=0.59$.

fragments (Tuazon et al., 1994), leading to a host of products including nitroalkanes, aldehydes, and imines.

2. The ozonolysis of particles of primary, aliphatic amines may represent a source of $\mathrm{NO}_{2}, \mathrm{NO}_{3}$ and nitric acid ion clusters, even at ozone concentrations that correspond to a polluted suburban-urban troposphere (National Research Council, 1991). The experimental data reported herein suggests that progressive oxidation of amines leads to $\mathrm{NO}_{2}$ formation, with subsequent formation $\mathrm{NO}_{3}$ through progressive oxidation (as described above) and finally nitric acid ion clusters. As described in Reactions 4a-b, an alternative pathway to nitric acid, and subsequently the nitric acid ion cluster, is via the reaction of $\mathrm{NO}_{2}$ and $\mathrm{NO}_{3}$ to $\mathrm{N}_{2} \mathrm{O}_{5}$, followed by hydrolysis. This may help explain, in part, the mechanism by which organic nitrogen in fog water and aerosols acts as a source of $\mathrm{NO}_{\mathrm{x}}$ and $\mathrm{NO}_{3}$ during exposure to ozone (Zhang and Anastasio, 2003). Future emphasis will be placed on quantification of $\mathrm{NO}_{2}, \mathrm{NO}_{3}$, and the nitric acid ion clusters via PERCI for the ozonolysis of a wider array of particle bound organic species that contain amine nitrogen. This is inherently challenging because many of the anticipated products (i.e. $\mathrm{NO}_{2}$ and $\mathrm{NO}_{3}$ ) do not have well-established capture crosssections for very low energy photoelectrons. We will also investigate the effects of relative humidity on the formation of nitric acid ion clusters.

The experiments described in this work have lead to several significant observations in the heterogeneous ozonolysis of mixed particles containing amines: 
1. Secondary and tertiary amides and possibly imines are potentially important reaction products of the heterogeneous ozonolysis of aliphatic primary amines in particles, when SCI can be generated in situ to these mediums. These products are evident even at relatively low ozone exposures for relatively short reaction times. This implies that in regions where there is a high atmospheric input of amines (i.e. near animal husbandry operations (Schade and Crutzen, 1995)), there may be an enhanced incorporation of these nitrogen-containing species into particles. CI have been shown to form and react near or on the surface of ozonized OL particles (Hearn et al., 2005; Smith et al., 2002; Moise and Rudich, 2002; Katrib et al., 2004). When gas-phase amines partition to the surface of an ozonized particle that contains SCI and/or secondary ozonides, they may react via Route 2 and/or 3 to form the lower volatility amides. This is evidenced by our observation of these high molecular weight products even at low ozone exposures (cf. Fig. 4a). These reactions represent new pathways by which amine nitrogen may be converted to lower volatility particle bound nitrogen. They may also help explain the mechanism of forming nitrogen enriched HULIS (Decesari et al., 2006; Likens and Galloway, 1983) and may be important in the atmospheric aging of organic aerosols. Moreover, amides, compared to other acylation products such as esters, are relatively stable to hydrolysis (Satchell, 1963), resulting in the potentially long atmospheric lifetime of these nitrogen containing species in particles. The viability of gas-toparticle conversions of amine nitrogen via these mechanisms will be the focal point of upcoming environmental chamber experiments in our laboratory where we will examine the effects of prolonged ozone exposure (hours to days) of more common atmospheric amines (i.e. ethyl amines) in the presence of unsaturated acids at ozone levels in accord with a polluted suburban-urban troposphere.

2. Although amide production is in accord with wellestablished solution acylation reactions (i.e., between the carboxylic acids and the amine (Satchell, 1963)), our data implies that the major pathway(s) in ozonized particles of ODA (HDA) + OL is through the reaction of SCI and/or secondary ozonides with the amine. This may have ramifications to source apportionment where it has been suggested that amides can be utilized as molecular markers (Simoneit et al., 2003) for biomass burning events, since they can be generated by standard (i.e. Route 1) acylation under pyrolysis. Although we agree with the importance of this route of amide formation under biomass burning conditions, we need to establish the viability of the role of secondary chemistry of ozonolysis in sequestering amine nitrogen into particulate matter via amide formation (i.e. Routes 2

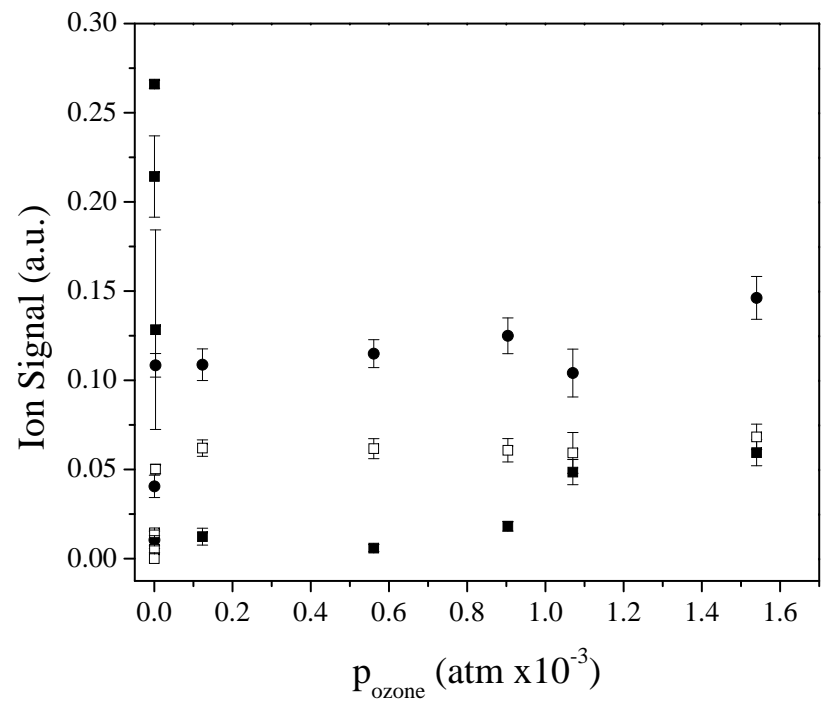

Fig. 8. OL decay and the formation of amides and imine in ozonized mixed particles of ODA/OL: $(\boldsymbol{\square})$ OL; ( $\square$ ) $438 \mathrm{~m} / \mathrm{z}$ secondary amide; and $(\bullet)$ integrated ion intensity for all amides and imines (Compounds 1-6) measured. Mole fractions, $\chi$, were $\chi \mathrm{ODA}=0.41$ and $\chi_{\mathrm{OL}}=0.59$.

and 3). These routes, if important competing pathways to amide formation through acylation would indicate that amides may also be molecular markers for regions that have concurrent high levels of ozone and amine input, i.e. animal husbandry operations near polluted suburban-urban environments.

3. There is evidence of solid surface or highly viscous liquid layer formation in ODA + OL at high ozone exposures. This may impede the diffusion of ozone into the particle causing retention of OL at these very high exposures, where it would be totally consumed in single component particles of OL. This observation and similar ones by others (Nash et al., 2006) in fatty acid rich particulate, along with the retention of OL even at high exposures, may help elucidate the disparity that exists between the lifetime of OL measured in the field vs. in the laboratory (Zahardis and Petrucci, 2007). The formation of high molecular weight amides is likely to occur in meat-cooking aerosols that are rich in both fatty acids and amines and that are formed under conditions of high temperature (facilitating Route 1 amide formation). Amide formation is especially significant when generated in a polluted, ozone rich troposphere (facilitating amide formation via Routes 2 and 3). The prolonged lifetime of OL in real meat cooking aerosols vs. single-component particulate OL matter has also been demonstrated experimentally (Hearn and Smith, 2006). Although we only observe the solid surface or highly viscous liquid layer formation in the OL + ODA reaction system under conditions of very high ozone 
exposure $\left(1 \times 10^{-4} \mathrm{~atm}_{3}, 17 \mathrm{~s}\right.$ reaction time $)$, we need to investigate the effects of prolonged exposure of particles to lower levels of ozone $\left(\sim 10^{-7}\right.$ atm $\left.\mathrm{O}_{3}\right)$ with experiments in environmental chambers. Although not explored in this work, other condensed phase thermochemical effects that may cause a prolonged lifetime of OL and other unsaturated components of real atmospheric aerosols, such as gel or semisolid formation, or Ostwald ripening in amide enriched aerosols needs to be explored as well.

Acknowledgements. This material is based upon work supported by the National Science Foundation under Grant No. ATM0440074. The authors are grateful also to the NASA-VT Space Grant Consortium/NASA EPSCoR for financial assistance.

Edited by: Y. Rudich

\section{References}

Angelino, S., Suess, D. T., and Prather, K. A.: Formation of aerosol particles from reactions of secondary and tertiary alkylamines: Characterization by aerosol time-of-flight mass spectrometry, Environ. Sci. Technol., 35(15), 3130-3138, 2001.

Bachman, G. B. and Strawn, K. G.: Ozone oxidation of primary amines to nitroalkanes, J. Org. Chem., 33(1), 313-315, 1968.

Bailey, P. S.: Ozonation in Organic Chemistry. New York, Academic Press, 1978.

Bailey, P. S., Carter Jr., T. P., and Southwick, L. M.: Ozonation of amines. VI. Primary amines, J. Org. Chem., 37(19), 2997-3004, 1972.

Beddows, D. C. S., Donovan, R. J., Harrison, R. M., Heal, M. R., Kinnersley, R. P., King, M. D., Nicholson, D. H., and Thompson, K. C.: Correlations in the chemical composition of rural background atmospheric aerosol in the UK determined in real time using time-of-flight mass spectrometry, J. Environ. Monitor., 6, 124-133, 2004.

Broekhuizen, K. E., Thornberry, T., Kumar, P. P., and Abbatt, J. P. D.: Formation of cloud condensation nuclei by oxidative processing: Unsaturated fatty acids, J. Geophys. Res., 109, D24206, doi:10.1029/2004JD005298, 2004.

Decesari, S., Fuzzi, S., Facchini, M. C., Mircea, M., Emblico, L., Cavalli, F., Maenhaut, W., Chi, X., Schkolnik, G., Falkovich, A., Rudich, Y., Claeys, M., Pashynska, V., Vas, G., Kourtchev, I., Vermeylen, R., Hoffer, A., Andreae, M. O., Tagliavini, E., Moretti, F., and Artaxo, P.: Characterization of the organic composition of aerosols from Rondônia, Brazil, during the LBASMOCC 2002 experiment and its representation through model compounds, Atmos. Chem. Phys., 6, 375-402, 2006, http://www.atmos-chem-phys.net/6/375/2006/.

DeMore, W. B., Sander, S. P., Golden, D. M., Hampson Jr., R. F., Kurylo, M. J., Howard, C. J., Ravishankara, A. R., Kolb, C. E., and Molina, M. J.: Chemical kinetics and photochemical data for use in stratospheric modeling, Evaluation No. 12, Jet Propolsion Laboratory Publishing, Pasadena, 1997

Ervin, K. M., Ho, J., and Lineberger, W. C.: Ultraviolet photoelectron spectrum of $\mathrm{NO}_{2}^{-}$, J. Phys. Chem., 92, 5405-5412, 1988.
Fehsenfeld, F. C., Howard, C. J., and Schmeltekopf, A. L.: Gas phase ion chemistry of $\mathrm{HNO}_{3}$, J. Chem. Phys., 63, 2835-2841, 1975.

Filipy, J., Rumburg, B., Mount, G., Westberg, H., and Lamb, B.: Identification and quantification of volatile organic compounds from a dairy, Atmos. Environ., 40, 1480-1494, 2006.

Finlayson-Pitts, B. J. and Pitts Jr., J. N.: Chemistry of the Upper and Lower Atmosphere, Academic Press, NYC, USA, 1999.

Finlayson-Pitts, B. J., Wingen, L. M., Sumner, A. L., Syomin, D., and Ramazan, K. A.: The heterogeneous hydrolysis of $\mathrm{NO}_{2}$ in laboratory systems and in outdoor and indoor atmospheres: An integrated mechanism, Phys. Chem. Chem. Phys., 5, 223-242, 2003.

Galloway, J. N., Dentener, F. J., Capone, D. G., Boyer, E. W., Howarth, R. W., Seitzinger, S. P., Asner, G. P., Cleveland, C. C., Green, P. A., Holland, E. A., Karl, D. M., Michaels, A. F., Porter, J. H., Townsend, A. R., and Vörösmarty, C. J.: Nitrogen cycles: Past, present, and future, Biogeochemistry, 70, 153-226, 2004.

Gilman, J. P., Hsieh, T., and Meisels, G. G.: Competition between isomerization and fragmentation of gaseous ions. II. Nitromethane and methylnitrite ions, J. Chem. Phys., 78, 1174 1179, 1983.

Gross, D. S., Gälli, M. E., Kalberer, M., Prevot, A. S. H., Dommen, J., Alfarra, M. R., Duplissy, J., Gaeggeler, K., Gascho, A., Metzger, A., and Baltensperger, U.: Real-time measurement of oligomeric species in secondary organic aerosol with the timeof-flight mass spectrometer, Anal. Chem., 78, 2130-2137, 2006.

Hearn, J. D. and Smith, G. D.: Kinetics and product studies for the ozonolysis reactions of organic particles using aerosol CIMS, J. Phys. Chem. A, 108, 1019-1029, 2004.

Hearn, J. D., Lovett, A. J., and Smith, G. D.: Ozonolysis of oleic acid particles: Evidence for a surface reaction and secondary reactions involving Criegee intermediates, Phys. Chem. Chem. Phys., 7, 501-511, 2005.

Hearn, J. D. and Smith, G. D.: Reactions and mass spectra of complex particles using aerosol CIMS, Int. J. Mass Spectrom., 258, 95-103, 2006.

Heitmann, H. and Arnold, F.: Composition measurements of tropospheric ions, Nature, 306, 747-751, 1983.

Hine, J., and Via, F. A.: Kinetics of the formation of imines from isobutyraldehyde and primary aliphatic amines with polar substituents, J. Am. Chem. Soc., 94, 190-194, 1972.

Hine, J., Cholod, M. S., and Chess Jr., W. K.: Kinetics of the formation of imines from acetone and primary amines. Evidence for internal acid-catalyzed dehydration of certain carbinolamines, J. Am. Chem. Soc., 95, 4270-4276, 1973.

Hirokawa, K., Li, Z., and Tanaka, A.: Role of electronegativity in the qualitative pattern interference of the TOF-SIMS fragment pattern of inorganic compounds, Fresen. J. Anal. Chem., 370, 348-357, 2001.

Hrvačić, B., Bošnjak, B., Tudja, M., Mesić, M., and Merćep, M.: Applicability of an ultrasonic nebulization system for the airways delivery of beclomethasone dipropionate in a murine model of asthma, Pharm. Res., 23, 1765-1775, 2006.

Hung, H.-M., Katrib, Y., and Martin, S. T.: Products and mechanisms of the reaction of oleic acid with ozone and nitrate radical, J. Phys. Chem. A, 109, 4517-4530, 2005.

Hung, H.-M. and Ariya, P.: Oxidation of oleic acid and oleic 
acid/sodium chloride(aq) mixture droplets with ozone: Changes in hygroscopicity and role of secondary reactions, J. Phys. Chem. A, 111, 620-632, 2007.

Katrib, Y., Martin, S. T., Hung, H.-M., Rudich, Y., Zhang, H., Slowik, J. G., Davidovits, P., Jayne, J. T., and Worsnop, D. R.: Products and mechanisms of ozone reactions with oleic acid for aerosol particles having core-shell morphologies, J. Phys. Chem. A, 108, 6686-6695, 2004.

Katrib, Y., Biskos, G., Buseck, P. R., Davidovits, P., Jayne, J. T., Mochida, M., Wise, M. E., Worsnop, D. R., and Martin, S. T.: Ozonolysis of mixed oleic-acid/stearic acid particles: Reaction kinetics and chemical morphology, J. Phys. Chem. A, 109, 10910-10919, 2005.

Kawamura, K., Ishimura, Y., and Yamazaki, K.: Four years’ observations of terrestrial lipid class compounds in marine aerosols from the western North Pacific, Global Biogeochem. Cy., 17, 1003, doi:10.1029/2001GB001810, 2003.

Keinan, E. and Mazur, Y.: Dry ozonation of amines. Conversion of primary amines to nitro compounds, J. Org. Chem., 42, 844-847, 1977.

King, M. D., Thompson, K. C., and Ward, A. D.: Laser tweezers raman study of optically trapped aerosol droplets of seawater and oleic acid reacting with ozone: Implications for cloud-droplet properties, J. Am. Chem. Soc., 126, 16 710-16711, 2004.

LaFranchi, B. W. and Petrucci, G. A.: Photoelectron resonance capture ionization (PERCI): A novel technique for the softionization of organic compounds, J. Am. Soc. Mass Spectrom., 15, 424-430, 2004.

LaFranchi, B. W., Zahardis, J., and Petrucci, G. A.: Photoelectron resonance capture ionization mass spectrometry: A soft ionization source for mass spectrometry of particle-phase organic compounds, Rapid Commun. Mass Sp., 18, 2517-2521, 2004.

LaFranchi, B. W. and Petrucci, G. A.: A comprehensive characterization of photoelectron resonance capture ionization aerosol mass spectrometry for the quantitative and qualitative analysis of organic particulate matter, Int. J. Mass Spectrom., 258, 120-133, 2006.

Likens, G. E. and Galloway, J. N.: The composition and deposition of organic carbon precipitation, Tellus, 35B, 16-24, 1983.

Liu, P., Ziemann, P. J., Kittelson, D. B., and McMurry, P. H.: Generating particle beams of controlled dimensions and divergence: II. Experimental evaluation of particle motion in aerodynamic lenses and nozzle expansions, Aerosol Sci. Tech., 22, 314-324, 1995a.

Liu, P., Ziemann, P. J., Kittelson, D. B., and McMurry, P. H.: Generating particle beam of controlled dimensions and divergence: I. Theory of particle motion in aerodynamic lenses and nozzle expansions, Aerosol Sci. Tech., 22, 293-313, 1995 b.

Lohmann, U. and Feichter, J.: Global indirect aerosol effects: A review, Atmos. Chem. Phys., 5, 715-737, 2005, http://www.atmos-chem-phys.net/5/715/2005/.

Mace, K. A., Artaxo, P., and Duce, R. A.: Water-soluble organic nitrogen in Amazon Basin aerosols during the dry (biomass burning) and wet seasons, J. Geophys. Res., 108, 4512, doi:10.1029/2003JD003557, 2003.

Mäkelä, J. M., Yli-Koivisto, S., Hiltunen, V., Seidl, W., Swietlicki, E., Teinilä, K., Sillanpää, M., Koponen, I. K., Paatero, J., Rosman, K., and Hämeri, K.: Chemical composition of aerosol during particle formation events in boreal forest, Tellus, 53B, 380
393, 2001.

Martin, S.: Interactive comment on "The oleic acid-ozone heterogeneous reaction system: Products, kinetics, secondary chemistry, and atmospheric implications of a model system - a review", Atmos. Chem. Phys. Discuss., 6, S4976-S4978, 2006 a.

Martin, S.: Interactive comment on "The oleic acid-ozone heterogeneous reaction system: Products, kinetics, secondary chemistry, and atmospheric implications of a model system - a review", Atmos. Chem. Phys. Discuss., 6, S4979-S4980, 2006 b.

McGregor, K. G. and Anastasio, C.: Chemistry of fog waters in California's Central Valley: 2. Photochemical transformations of amino acids and alkyl amines, Atmos. Environ., 35, 1091-1104, 2001.

Milne, P. J. and Zika, R. G.: Amino acid nitrogen in atmospheric aerosols: Occurrence, sources and photochemical modifications, J. Atmos. Chem, 16, 361-398, 1993.

Mochida, M., Kitamori, Y., Kawamura, K., Nojiri, Y., and Suzuki, K.: Fatty acids in the marine atmosphere: Factors governing their concentrations and evaluation of organic films on sea-salt particles, J. Geophys. Res., 107, 4325, doi:10.1029/2001JD001278, 2002.

Mochida, M., Katrib, Y., Jayne, J. T., Worsnop, D. R., and Martin, S. T.: The relative importance of competing pathways for the formation of high-molecular-weight peroxides in the ozonolysis of organic aerosol particles, Atmos. Chem. Phys., 6, 4851-4866, 2006, http://www.atmos-chem-phys.net/6/4851/2006/.

Modelli, A. and Venuti, M.: Empty level structure and dissociative electron attachment in gas-phase nitro derivatives, Int. J. Mass Spectrom., 205, 7-16, 2001.

Moise, T. and Rudich, Y.: Reactive uptake of ozone by aerosolassociated unsaturated fatty acids: Kinetics, mechanism, and products, J. Phys. Chem. A, 106, 6469-6476, 2002.

Murphy, S. M., Sorooshian, A., Kroll, J. H., Ng, N. L., Chhabra, P., Tong, C., Surratt, J. D., Knipping, E., Flagan, R. C., and Seinfeld, J. H.: Secondary aerosol formation from atmospheric reactions of aliphatic amines, Atmos. Chem. Phys., 7, 2313-2337, 2007, http://www.atmos-chem-phys.net/7/2313/2007/.

Nash, D. G., Tolocka, M. P., and Baer, T.: The uptake of $\mathrm{O}_{3}$ by myristic acid - oleic acid mixed particles: Evidence for solid surface layers, Phys. Chem. Chem. Phys., 8, 4468-4475, 2006.

National Research Council: Rethinking the ozone problem in urban and regional air pollution, National Academy Press, Washington, D. C., 1991.

Nazin, G. M. and Manelis, G. B.: Thermal decomposition of aliphatic nitro-compounds, Russ. Chem. Rev., 63, 313-322, 1994.

Neff, J. C., Holland, E. A., Dentener, F. J., McDowell, W. H., and Russell, K. M.: The origin, composition and rates of organic nitrogen deposition: A missing piece of the nitrogen cycle?, Biogeochemistry, 57/58, 99-136, 2002.

Ozensoy, E., Peden, C. H. F., and Szanyi, J.: $\mathrm{NO}_{2}$ adsorption on ultrathin $\theta-\mathrm{Al}_{2} \mathrm{O}_{3}$ films: Formation of nitrite and nitrate species, J. Phys. Chem. B, 109, 15 977-15 984, 2005.

Perkins, M. D. and Eisele, F. L.: First mass spectrometric measurements of atmospheric ions at ground level, J. Geophys. Res., 89, 9649-9657, 1984.

Petrucci, G. A., Farnswoth, P. B., Cavalli, P., and Omenetto, N.: A differentially pumped particle inlet for sampling of atmospheric 
aerosols into a time-of-flight mass spectrometer: Optical characterization of the particle beam, Aerosol Sci. Technol., 33, 105$121,2000$.

Pitts Jr, J. N., Sanhueza, E., Atkinson, R., Carter, W. P. L., Winer, A. M., Harris, G. W., and Plum, C. N.: An investigation of the dark formation of nitrous acid in environmental chambers, Int. J. Chem. Kinet., 16, 919-939, 1984.

Rabaud, N. E., Ebeler, S. E., Ashbaugh, L. L., and Flocchini, R. G.: Characterization and quantification of odorous and non-odorous volatile organic compounds near a commericial dairy in California, Atmos. Environ., 37, 933-940, 2003.

Ramazan, K. A., Wingen, L. M., Miller, Y., Chaban, G. M., Gerber, R. B., Xantheas, S. S., and Finlayson-Pitts, B. J.: New experimental and theoretical approach to the heterogeneous hydrolysis of $\mathrm{NO}_{2}$ : Key role of molecular nitric acid and its complexes, J. Phys. Chem. A, 110, 6886-6897, 2006.

Reynolds, J. C., Last, D. J., McGillen, M., Nijs, A., Horn, A. B., Percival, C., Carpenter, L. J., and Lewis, A. C.: Structural analysis of oligomeric molecules formed from the reaction products of oleic acid ozonolysis, Environ. Sci. Technol., 40, 6674-6681, 2006.

Robinson, A. L., Subramanian, R., Donahue, N. M., BernardoBricker, A., and Rogge, W. F.: Source apportionment of molecular markers and organic aerosol. 3. Food cooking emissions, Environ. Sci. Technol., 40, 7820-7827, 2006.

Rogge, W. F., Hildemann, L. M., Mazurek, M. A., Cass, G. R., and Simoneit, B. R. T.: Sources of fine organic aerosol. 1. Charbroilers and meat cooking operations, Environ. Sci. Technol., 25, 1112-1125, 1991.

Satchell, D. P. N.: An outline of acylation, Q. Rev. Chem. Soc., 17, 160-203, 1963.

Schade, G. W. and Crutzen, P. J.: Emission of aliphatic amines from animal husbandry and their reactions: Potential source of $\mathrm{N}_{2} \mathrm{O}$ and HCN, J. Atmos. Chem, 22, 319-346, 1995.

Schauer, J. J., Kleeman, M. J., Cass, G. R., and Simoneit, B. R.: Measurement of emissions from air pollution sources. 1. $\mathrm{C}_{1}$ through $\mathrm{C}_{29}$ organic compounds from meat charbroiling, Environ. Sci. Technol., 33, 1566-1577, 1999.

Schauer, J. J., Kleeman, M. J., Cass, G. R., and Simoneit, B. R. T.: Measurement of emissions from air pollution sources. 4. $C_{1}-C_{27}$ organic compounds from cooking with seed oils, Environ. Sci. Technol., 36, 567-575, 2002.

Sekimoto, K. and Takayama, M.: Influence of needle voltage on the formation of negative core ions using atmospheric pressure corona discharge in air, Int. J. Mass Spectrom., 261, 38-44, 2007.

Shilling, J. E., King, S. M., Mochida, M., Worsnop, D. R., and Martin, S. T.: Mass spectral evidence that small changes in composition caused by oxidative aging processes alter aerosol $\mathrm{ccn}$ properties, J. Phys. Chem. A, 111, 3358-3368, 2007.

Simoneit, B. R. T., Rushdi, A. I., bin Abas, M. R., and Didyk, B. M.: Alkyl amides and nitriles as novel tracers for biomass burning, Environ. Sci. Technol., 37, 16-21, 2003.

Smith, G. D., Woods III, E., DeForest, C. L., Baer, T., and Miller, R. E.: Reactive uptake of ozone by oleic acid aerosol particles: Application of single-particle mass spectrometry to heterogeneous reaction kinetics, J. Phys. Chem. A, 106, 8085-8095, 2002.

Tan, P. V., Evans, G. J., Tsai, J., Owega, S., Fila, M. S., Malpica, O., and Brook, J. R.: On-line analysis of urban particulate matter focusing on elevated wintertime aerosol concentrations, Environ.
Sci. Technol., 36, 3512-3518, 2002.

Tervahattu, H., Juhanoja, J., and Kupiainen, K.: Identification of an organic coating on marine aerosol particles by TOF-SIMS, J. Geophys. Res., 107(D16), doi:10.1029/2001JD001403, 2002.

Tervahattu, H., Juhanoja, J., Vaida, V., Tuck, A. F., Niemi, J. V., Kupiainen, K., Kulmala, M., and Vehkamäki, H.: Fatty acids on continental sulfate aerosol particles, J. Geophys. Res., 110, D06207, doi:10.1029/2004JD005400, 2005.

Tuazon, E. C., Atkinson, R., Aschmann, S. M., and Arey, J.: Kinetics and products of the gas-phase reactions of $\mathrm{O}_{3}$ with amines and related compounds, Res. Chem. Intermediat., 20, 303-320, 1994.

Wahner, A., Mentel, T. F., Sohn, M., and Stier, J.: Heterogeneous reaction of $\mathrm{N}_{2} \mathrm{O}_{5}$ on sodium nitrate aerosol, J. Geophys. Res., 103, 31 103-31 112, 1998.

Wang, H., Kawamura, K., and Shooter, D.: Wintertime organic aerosols in Christchurch and Auckland, New Zealand: Contributions of residential wood and coal burning and petroleum utilization, Environ. Sci. Technol., 40, 5257-5262, 2006.

Zahardis, J., LaFranchi, B. W., and Petrucci, G. A.: Photoelectron resonance capture ionization-aerosol mass spectrometry of the ozonolysis products of oleic acid particles: Direct measure of higher molecular weight oxygenates, J. Geophys. Res., 110, D08307, doi:10.1029/2004JD005336, 2005.

Zahardis, J., LaFranchi, B. W., and Petrucci, G. A.: Direct observation of polymerization in the oleic acid - ozone heterogeneous reaction system by photoelectron resonance capture ionization aerosol mass spectrometry, Atmos. Environ., 40, 16611670, 2006a.

Zahardis, J., LaFranchi, B. W., and Petrucci, G. A.: The heterogeneous reaction of particle-phase methyl esters and ozone elucidated by photoelectron resonance capture ionization: Direct products of ozonolysis and secondary reactions leading to the formation of ketones, Int. J. Mass Spectrom., 253, 38-47, 2006b.

Zahardis, J., LaFranchi, B. W., and Petrucci, G. A.: Photoelectron resonance capture ionization mass spectrometry of fatty acids in olive oil, Eur. J. Lipid Sci. Tech., 108, 925-935, 2006c.

Zahardis, J. and Petrucci, G. A.: The oleic acid-ozone heterogeneous reaction system: Products, kinetics, secondary chemistry, and atmospheric implications of a model system - a review, Atmos. Chem. Phys., 7, 1237-1274, 2007, http://www.atmos-chem-phys.net/7/1237/2007/.

Zhang, Q. and Anastasio, C.: Conversion of fogwater and aerosol organic nitrogen to ammonium, nitrate, and $\mathrm{NO}_{\mathrm{x}}$ during exposure to simulated sunlight and ozone, Environ. Sci. Technol., 37, 3522-3530, 2003.

Zhao, Y., Hu, M., Slanina, S., and Zhang, Y.: Chemical compositions of fine particulate organic matter emitted from Chinese cooking, Environ. Sci. Technol., 41, 99-105, 2007.

Ziemann, P. J.: Aerosol products, mechanisms, and kinetics of heterogeneous reactions of ozone with oleic acid in pure and mixed particles, Faraday Discuss., 130, 469-490, 2005. 